\title{
SOBRE LAZER, TEMPO E TRABALHO \\ NA SOCIEDADE DE CONSUMO
}

Ms. Cristina Borges de Oliveira

Integrante do Grupo de Estudos e Pesquisas

Corpo, Infância e Escola da FEF/UFG

\section{Resumo}

O presente texto insere-se em uma perspectiva de discussão crítica da Educação Física acerca da temática, lazer, na expectativa de contribuir para a ampliação da necessária reflexão sobre a importância, características, conseqüências e possibilidades desta temática na sociedade de consumo. Para tanto, optamos pela abordagem dos conceitos de tempo e trabalho na sociedade moderna bem como a relação desta trilogia com o direito de participação das minorias. Estes conceitos são fundamentais para o entendimento dos aspectos caracterizadores do lazer como o aspecto da cultura.

Palavras-Chave: Lazer; Tempo; Trabalho.

Nas últimas décadas, a indústria do entretenimento - sinônimo de lazer para muitos - seduz o consumidor, sugerindo-lhe as sessões adequadas para sua satisfação. Vê-se então a idéia reducionista do lazer sendo alimentada e veiculada pelos meios de comunicação de massa sendo que mal interpretada, a idéia é vendida, na maioria dos casos, como atividade física/esportiva, artística/cultural, recreativa, ao ar livre e/ou em espaços intencionalmente construídos para tais fins, com um grande número de pessoas bonitas e felizes, e uma parafernália de produtos que referenciam, socialmente, a qualidade de tal lazer.

Capra (1985) comenta a ação sugestionadora dos meios de comunicação de massa, alertando que a finalidade exclusiva da mídia é o condicionamento do público ao consumo de toda espécie de bem e/ou serviço, dentre os quais destacamos o lazer. Ousando ir além, recorro aqui a Ianni (1999), ao entender que na era da globalização, a mídia representa a articulação entre várias instâncias hegemônicas, assumindo o papel de príncipe eletrônico. O príncipe é o arquétipo que possui a capacidade de construir hegemonias, simultaneamente, a organização, consolidação e desenvolvimento de 
soberanias. Tipo ideal criado por Maquiavel ${ }^{1}$ como figura política, pessoa, o príncipe assume em Gramsci a identidade do partido político como intelectual orgânico à classe trabalhadora enquanto que atualmente a mídia assume a identidade de príncipe eletrônico - expressando segundo Ianni (1999, p. 9) “[...] a visão de mundo prevalecente nos blocos de poder predominantes, em escala nacional, regional e mundial, habilmente articuladas."

Sob esta ótica, o papel assumido pela mídia amplia-se uma vez que pressupõe a articulação entre várias esferas e instâncias de poder político que exerce influência relevante na direção e organização da vida social. Em especial, a televisão, como meio privilegiado - por sua penetração e fascínio - do poder deste príncipe eletrônico assume dimensões psicossociais, sócio-culturais e político-econômicas atingindo atividades e imaginários individuais e coletivos, sendo um dos principais veículos de divulgação de posições alienantes sobre o lazer.

Em tal contexto se estabelece um conhecimento restrito dos conteúdos do lazer, de seus desdobramentos, dos valores que propicia e das atitudes que o envolve para ajudar na reflexão que envolve o lazer em uma preocupação maior, recorro aqui a Gutierrez (2001, p. 98)

A discussão sobre a falência do poder macro-sociológico
determinante da categoria trabalho, portanto, nos coloca
diante da necessidade de encarar a questão do objeto lazer e
procurar situá-la, o mais claramente possível, no contexto
mais amplo da compreensão das relações sociais e políticas
contemporâneas.

Há um escasso domínio e conhecimento sobre as possibilidades, a partir do lazer, de mudanças de atitudes e valores frente aos grandes problemas sociais como preconceito, racismo, intolerância de ordem religiosa, sexual, cultural e política entre outros. Assim, apesar das crescentes discussões e sua enorme utilização, o conceito de lazer ainda permanece restrito aos níveis de entendimento que contém em seu gênero a visão conservadora que não questiona a lógica capitalista e neoliberal de pensar o

JAPIASSÚ, H.; MARCONDES, D., Dicionário básico de filosofia, Rio de Janeiro: Jorge Zahar, 1996, p. 173 - "O príncipe deveria ter uma tríplice missão: a: tomar o poder; b) assegurar a estabilidade política; c) construir a República unificada. Maquiavel viu em Lourenço Médici a figura desse príncipe. Deveria ser um herói trágico, impiedoso e astucioso, resoluto e frio, porque esta era a única maneira de controlar a instabilidade política e a perversão dos homens, a fim de que fosse instaurada a cidade justa". 
mundo. Tal visão pode ser identificada na ótica funcionalista que perpassa o conceito de lazer e está presente, especificamente, nas abordagens:

$>$ Compensatória: que objetiva compensar o que o trabalho retira do indivíduo e do grupo principalmente através do lazer;

$>$ Utilitarista: que procura recuperar a força de trabalho do sujeito a partir do lazer desconsiderando todas as outras variáveis que influem nesta recuperação;

> Moralista: através do lazer, objetiva-se afastar as pessoas das drogas lícitas e ilícitas e dos pensamentos e práticas consideradas perniciosas, discurso bastante difundido pelos segmentos religiosos e;

> Romântica: cujo entendimento sobre o lazer resguarda um saudosismo inibidor de novas práticas a partir de uma postura conservadora $\mathrm{e}$ às vezes retrograda.

Encaramos como necessidade essencial avançarmos no sentido de um entendimento mais amplo sobre o lazer que considere suas relações com o mundo do trabalho e da cultura e, principalmente, suas possibilidades de transformar qualitativamente a sociedade humana a partir da perspectiva da inclusão sócio-cultural também dos grupos marginalizados como é o caso dos deficientes. Em acordo com Bramante (1992), o significado do lazer deve ser debatido tanto no âmbito do senso comum como no da própria universidade para que todos possam compreender sua importância na vida do indivíduo e da coletividade na sociedade contemporânea, notadamente, nos países do terceiro mundo onde o lazer torna-se muito mais uma aspiração do que uma realidade.

A partir de uma visão materialista-dialética, o lazer, para as massas excluídas, apresenta-se unicamente como uma possibilidade/aspiração e não enquanto uma realidade histórica. Faz-se mister à reflexão e discussão sobre o lazer, sem que haja discriminação para que ocorra uma contraposição ao discurso hegemônico acerca da temática. Gutierrez (2001, p. 99) chama a atenção discorrendo sobre a dificuldade de situar o lazer, enquanto objeto, em algum espaço delimitado da academia. 
De uma forma geral, existe uma tendência bastante visível da pesquisa em sociologia do lazer, seja recuperando o trabalho de autores como Norbert Elias, ou pela vertente da pesquisa de questões culturais, numa perspectiva pós-modernidade ou não. [...] trata-se, neste momento, de um objeto pesquisado multidisciplinar e que ainda não foi monopolizado por nenhum dos campos acadêmicos constituídos tradicionalmente.

No intuito de apresentar uma definição escolhemos perspectivar o lazer enquanto tudo aquilo que se constitui em valor positivo, fim ou objetivo da ação humana. Como qualquer atitude e/ou atividade que proporcione bem-estar, vivenciada no tempo disponibilizado para tal. Tanto seja uma atitude/ação prática quanto contemplativa e que, referente aos conteúdos que a envolve, venha abranger os propósitos que formam a globalidade do ser humano como os aspectos lúdicos, intelectuais, interativos, criativos, estético, físico-esportivos, artísticos, sócio-culturais, afetivos, político, econômicos e todos se inter-relacionando.

Sobre o tempo disponível reservado ao lazer, o conceito aqui utilizado é aquele momento/tempo diferente do tempo dedicado ao trabalho e que está disponibilizado para uma atitude/atividade que se caracterize enquanto lazer. Consideramos, ainda, que lazer é direito de qualquer cidadão - inclusive daquele que é considerado deficiente -, independente de classe social, crença, idade, raça, gênero, orientação sexual ou estilo de vida. Marcellino (1995) traz-nos duas grandes considerações em torno do lazer, importantes para a ampliação de seu conceito: a especificidade abstrata e a especificidade concreta que envolve o tema. A saber, o entendimento do lazer unicamente em sua especificidade abstrata define a não consideração do conjunto de condicionantes sociais, políticas, econômicas, culturais entre outras que tendo como alicerce a questão sócio-econômica, gera e estimula, mascaradamente, as desigualdades quanto à apropriação pelo capital do tempo disponível do trabalhador tanto em quantidade de tempo quanto também em qualidade.

Tal situação reforça as abordagens funcionalistas, já mencionadas neste texto, e mantém a ordem social vigente. Isto quer dizer que, existem as possibilidades do lazer enquanto opção de ação social, mas o contexto em que as opções se inserem não possibilita o acesso da grande massa populacional em função da forte desigualdade estampada na realidade social. Estamos falando neste artigo dos deficientes que não 
tem oportunidade de trabalho, dos trabalhadores/as expropriados, dos aposentados/as, dos milhões de desempregados e miseráveis excluídos da dinâmica social. Considerando a própria dialética da questão, compreendemos que na sua especificidade concreta, o lazer é componente da cultura historicamente construída, na qual a participação cultural e o exercício da cidadania são a base para a renovação da sociedade.

Portanto, o lazer se insere como reivindicação e direito social, uma vez que, é resultado da sociedade urbana moderna sendo produto e agente de cultura. Esta visão ousada, orgânica à classe excluída do poder, enquanto direito se expressa na oferta de programas e projetos mantidos pelos poderes públicos que têm como princípio básico à possibilidade de participação democrática. Tais ações concretas quando destinadas a grupos específicos: pessoas que são alijadas do processo de participação social como, por exemplo, as pessoas deficientes, os idosos, as crianças especialmente aquelas muito pobres que vivem em situação de risco, pessoas portadoras de HIV entre outros, são, fundamentalmente importantes enquanto ações políticas que estimulam o exercício da cidadania.

A partir da consolidação de propostas de lazer coerentes e condizentes com a especificidade concreta de cada grupo, incrementa-se o exercício pleno da cidadania, através da participação ativa que buscando gerar novas possibilidades de ação, atua como um instrumento de educação, mobilização, organização, transformação e inclusão social, operacionalizando o alcance multidimensional, por suas relações com o mundo do trabalho, da educação e da cultura.

No entanto, devemos refletir sobre três pontos importante ao considerarmos as questões que Marcellino (1995) denomina de especificidade concreta, quais sejam:

$>$ As dificuldades e tabus sócio-culturais presentes na vida humana, que conturbam o acontecimento real do lazer, tanto dentro de uma mesma classe social quanto, principalmente, entre classes sociais diferentes:

$>$ A artificialização do lazer gerada pela indústria do entretenimento e meios de comunicação de massa;

$>$ A dominação do tempo através da forma capitalista neoliberal de pensar o mundo e de se posicionar diante dele. Neste sentido, 
fazemos destaque ao tempo em que se pode expressar a ludicidade diferente do tempo cotidiano, como nas civilizações ditas primitivas.

$\mathrm{Na}$ sociedade moderna o tempo se institucionalizou em intervalos de almoço, após o expediente, feriado, final de semana, férias e licença. Ilustrando com a mitologia grega, o tempo de Dionísio - deus grego dos ciclos vitais da alegria e do vinho, conhecido como Baco entre os romanos - entre em choque com o tempo de Prometeu, deus da civilização, do trabalho, da cultura e da repressão. Prometeu é o titã que dominou o fogo e o trouxe aos homens propiciando a civilização - e representa o princípio de desempenho, denominação que Marcuse $^{2}$ (1968) dá ao princípio da realidade freudiana, quando extrapola de sua dimensão individual para a dimensão histórico social. Neste contexto é impossível dissociar tempo e trabalho quando se reflete sobre o lazer e suas possibilidades de emancipação

\section{Dualidade Entre Tempo e Trabalho}

"Todos os dias quando acordo, não tenho mais o tempo que passou, mas, tenho muito tempo: Temos todo tempo do mundo. Todos os dias antes de dormir lembro e esqueço como foi o dia: Sempre em frente, não temos tempo a perder.” Apresento aqui o poeta e compositor Renato Russo (1982) na tentativa de traduzir a inquietação sobre o "Tempo Perdido".

Em uma perspectiva materialista histórico-dialética, o trabalho é a fonte de toda riqueza ${ }^{3}$, fonte também de prazer e de realização humanas. A categoria ontológica do marxismo permite entender que, ao realizar trabalho, o ser humano abandona a dependência para com a natureza e adentra na aventura do especificamente humano. Visto assim, o trabalho é produto do homem e ao mesmo tempo produtor do ser, da

${ }^{2}$ De acordo com Segundo JAPIASSÚ, H.; MARCONDES, D., Dicionário básico de filosofia, Rio de Janeiro: Jorge Zahar, 1996, p. 174. A principal contribuição de Marcuse à teoria crítica frankfurtiana pode ser considerada a relação que desenvolveu entre o pensamento de Marx e o de Freud, em uma interpretação que realça o sentido libertário tanto do marxismo quanto da teoria psicanalítica.

${ }^{3}$ Expressão usada por Engels para definir trabalho no texto O papel do trabalho na transformação do macaco em homem. 
cultura e civilização humana. Trabalhar, então, tem o significado de garantir as condições objetivas e subjetivas para a manutenção e o desenvolvimento da existência do homem, o que só poderia trazer satisfação e prazer.

No sistema produtivo capitalista, entretanto, o trabalho deixa de possuir tais possibilidades e expectativas e se consolida, na verdade, como fonte de desprazer, causando tensão e sofrimento, não permitindo a criatividade e até mesmo o usufruto de seus resultados. Todos estes motivos consolidam um tipo de trabalho, chamado por Marx de trabalho alienado, haja vista, que se baseia na exploração do tempo de trabalho do trabalhador e divide sua existência em tempos distintos, porém, articulados à dimensão da produção necessária ao capital.

Ao institucionalizar o tempo de trabalho, também se institucionaliza o tempo de não trabalho, ou seja, aquele no qual o trabalhador estaria, hipoteticamente, disponível para realizar outras atividades diferentes daquelas em que ele trabalha. Desta forma, se destila um tipo de organização social na qual o trabalho é a principal referência de tempo usada pelo indivíduo na orientação de sua vida: tudo gira em torno do trabalho e dos intervalos de tempo entre o exercício do mesmo.

Ocorre que na sociedade do conhecimento, pressupõe-se que o trabalho é realizado pelas máquinas e o ser humano é libertado para outras possibilidades de ação e atuação. Pressupõe-se que há tempo suficiente para o lazer, para a ampliação do conhecimento, para a vida familiar, etc. No entanto, como se tem comprovado a duras penas, na chamada sociedade do conhecimento, o trabalho das máquinas significa sempre desemprego - e, portanto, falta de renda. Tal processo é irreversível, uma vez que, os investimentos sempre se orientam em busca de mais tecnologia, maior qualificação do trabalhador e não na ampliação/criação de mais vagas e frentes de trabalho, o que coloca definitivamente grande parte da sociedade em um mundo de não trabalho.

O tempo de não trabalho pode acabar tornando-se um tempo de desconforto, uma vez, que por levar a um nada a fazer e uma conseqüente falta de renda retira do indivíduo o que ele acredita ser a determinante da sua condição humana. Não trabalhar retira dos sujeitos à possibilidade de exercerem a cidadania colocando-os à margem do contexto social. Os marginas, isto é, “[...] aqueles que foram mutilados físico ou 
socialmente (infelizes, bandidos, desvalidos) [...] trata-se daqueles que estão fora da esfera de poder, excluídos da vida econômica" Menezes (2000, p. 45) como retrata nosso maravilhoso artista de todos os tempos Chico Buarque de Hollanda na canção O Que Será? ${ }^{4}$

Destacamos as contradições encontradas com relação ao tempo, considerando a existência do tempo disponível em função de um tempo fixo obrigatório - tempo de trabalho - que recorta as demais ações do indivíduo. Observemos o Brasil, um país de crises, que traz em seu ranço a colonização exploratória, fato que se perpetua e ainda, se agrava com a adoção da política neoliberal que coloca o País cada dia mais dependente do capital estrangeiro sendo que, nesta situação, uma grande parte da população desfruta de vida subumana, enquanto uma pequena parte monopoliza grandes riquezas. $\mathrm{O}$ acesso e usufruto do lazer por parte dos que se encontram nos níveis inferiores da pirâmide social se coloca como uma das problemáticas fundamentais fruto da sociedade moderna. Uma reflexão crítica sobre os significados, possibilidades e limites do lazer não pode deixar de considerar as contradições e paradoxos suscitados pela dualidade tempo-trabalho.

Em especial, a não existência de trabalho que atenda a demanda da procura predispõe em abundância de tempo disponível para algumas pessoas, quais sejam, aquelas com algum tipo de deficiência, aquelas que não conseguem se colocar ou recolocar no mercado de trabalho por falta de instrução, escolarização e, ainda qualificação ou pela inexistência de vagas para todos. Pessoas que cumprem pena de detenção, crianças e jovens muito pobres, a grande massa de aposentados/as, entre outros. Para estas pessoas e grupos, a abundância de tempo disponível - o que, para a maioria, representa não trabalho - coloca também a impossibilidade do usufruto pleno do lazer uma vez que sem trabalho não há renda e sem renda reduzem-se as possibilidades de acesso e usufruto de práticas de lazer não alienadas e alienantes. È aqui que ganha importância a mídia televisiva de caráter comercial como espaço privilegiado de lazer.

${ }^{4}$ Uma análise detalhada da canção $\mathrm{O}$ que será? a qual aponta a convergência do erótico com o político encontra-se em MENEZES, A. B., Desenho mágico: poesia e política em Chico Buarque, São Paulo Ateliê, 1995. 
A definição do tempo de trabalho e do tempo de não-trabalho como critério que define as possibilidades de usufruto do lazer se esvaziam na chamada crise do trabalho e nas conseqüentes transformações no mundo da produção. Qual é afinal o tempo para o lazer, é a questão central, em um contexto marcado pela dualidade tempo-trabalho. Se considerarmos que, no sistema produtivo capitalista, o trabalho - por seu caráter alienado - permite tão somente a satisfação de certas necessidades básicas do ser humano como aquelas ligadas à manutenção e reprodução da vida material como alimentação, moradia, vestuário, pode-se concluir que o tempo de trabalho é o tempo destinado a conseguir as condições para a satisfação de tais necessidades.

No sistema produtivo capitalista aponta-se para o entendimento do tempo das necessidades como conceito mais abrangente que o termo tempo de trabalho. Dessa maneira busca-se incorporar ao tempo das necessidades todas as formas através dos quais o homem garante a manutenção de sua vida material e física. Tempo das necessidades é, então, aquele tempo que não possibilita o exercício e usufruto do lazer; é o tempo oposto ao lazer. Como conseqüência direta, o lazer é deslocado do tempo das necessidades ocorrendo em um tempo de não-necessidade, acarretando a compreensão de que ele (lazer) não se apresenta como necessidade para a manutenção e, mais além, desenvolvimento, da vida humana.

Aceitar a idéia que o lazer se apresenta como necessidade básica do ser humano é condição sine qua non para o estudo e a intervenção desta temática em qualquer que seja o espaço/tempo e sua destinação. É evidente além de comprovado pelas investigações científicas, que para a consolidação da existência humana faz-se mister a dimensão lúdica que é marca característica do lazer. O ser humano não mantém sua existência tão somente pela presença de condições materiais objetivas - alimentação, vestimenta, moradia -, embora tais condições sejam ponto de partida para a consolidação da sociabilidade humana. O ser humano não se mantém vivo, atuante, sujeito da própria história unicamente pela manutenção da vida física e material, mas incorpora a tal aspecto, de forma indissociável, a dimensão impar da vida subjetiva, a qual surge e se desenvolve a partir dos dados e exigências da matéria, mas o faz ativamente, modificando a própria matéria sobre a qual incide. 
Neste sentido, entender o lazer como uma necessidade menor e/ou supérflua é reforçar a dualidade clássica entre vida material e vida subjetiva, pois, ao não incluir as condições subjetivas - proporcionadas, entre outros, pelo lazer - como condições essenciais para a manutenção da existência humana, se estabelece uma separação de mundos que não são opostos, mas complementares. Como se fosse possível a existência do ser humano e da sociedade humana apenas e tão somente pela existência de condições materiais! Há, nesta perspectiva, uma preocupação com a manutenção da vida biológica, mas não a manutenção da vida especificamente humana, portanto, vida em sociedade e repleta de interações.

Pensar a questão das necessidades subjetivas de sonho, de lúdico e de imaginação não é tarefa fácil no contexto de uma sociedade como a nossa onde ter é muito mais importante, e tem um significado maior, do que o verbo ser. No entanto, é o desafio que urge em ser superado. O critério da prática a partir da reflexão sobre a prática e reformulação de valores e atitudes que a envolve, pode apresentar uma diretriz coerente na qual almejamos. É preciso observar em volta e perceber o mundo humano de maneira totalizante. Sendo o ser humano uma totalidade indivisível ${ }^{5}$, separar seu mundo em dois é o equivalente a reforçar os argumentos que legitimam a dominação e exploração de uns sobre outros. Voltando nossos olhares para as atividades humanas, encontramos a arte, que nesse caso, tem algo a dizer, na voz do poeta "[...] a gente não quer só comida, a gente quer comida, diversão e arte, diversão, balé."

O lazer, sob o nosso ponto de vista, é construção moderna, decorrente dos arranjos do modo de produção capitalista, porém, dada sua concreticidade, devemos lutar pelo direito a seu usufruto por todas as pessoas, considerando-o como necessidade tão básica quanto comida, casa e vestimenta. Por tais motivações, afirmamos que o termo tempo das necessidades não pode contemplar a abrangência pretendida, apesar das transformações no mundo do trabalho. Estas transformações têm o significado do aprofundamento das desigualdades entre dirigidos e dirigentes, vale dizer, entre os que

${ }^{5}$ GRAMSCI, A. A concepção dialética da história, Rio de Janeiro: Civilização Brasileira, 1995. Escreve que todo homem é filósofo - embora nem todos exerçam essa atividade profissional expressando a crença em uma totalidade humana indivisível, não fragmentária na qual os seres humanos podem ser considerados ou como práticos ou como intelectuais. 
realizam o trabalho intelectual e aqueles que executam o trabalho corporal, razão pelas quais devemos ampliar nossas compreensões a parâmetros não convencionais.

É importante salientar que o estudo antropológico tem sido utilizado como disciplina de apoio em várias áreas de conhecimento. A percepção do homem como totalidade indivisível, no entanto, relativo de forma quase absoluta a espaços e tempos específicos e o conhecimento detalhado sobre como distintas culturas interpretam o tempo e nele projetam sua existência, são áreas de pesquisa que tem elucidado a formulação de abordagens interdisciplinares significativas sobre a temática em discussão.

No frenético ritmo de vida capitalista, a formulação de idéias sobre a realidade histórica não dissocia tempo de trabalho, pois, é em função da força de trabalho vendida por uma determinada jornada de tempo que o capitalismo neoliberal se apropria do tempo do assalariado, recortando toda a vida do trabalhador, fazendo com que ele elimine outras possibilidades de criação. Assim, coloca-se cada vez mais longe o assalariado do que se produz, o capitalismo acumula riquezas, produz desigualdades e direciona a vida do trabalhador, a partir do tempo fixo e obrigatório, que estabelece as demais esferas de sua existência.

A antropologia apresenta o relógio como representação simbólica da existência fragmentada do ser humano e vem denunciando, historicamente, a mentalidade capitalista que transforma tempo em mercadoria e limita a este parâmetro as considerações do pensamento comum, negando o sentido envolvente e mágico do tempo que não possibilita ser quantificado, em destaque o tempo Dionisiano.

\section{Trabalho, Consumo e Lazer}

Importante atentarmos para a posição que ocupa o trabalho para o homem moderno a partir dos diferentes contextos históricos. Fazendo uma retrospectiva histórica rápida percebemos que a Grécia Antiga valorizava o ócio para seus cidadãos, o qual somente era possível pela exploração do trabalho escravo. Em um determinado momento, quem sabe por oposição aos ideais Greco-romanos de ócio, o cristianismo intentou recuperar o valor do trabalho, sem colocá-lo como valor maior da existência. 
Segundo especialistas, mesmo a literatura bíblica apresenta o trabalho como maldição, porém, contraditoriamente a expressão o trabalho dignifica o homem é de origem cristã e foi exacerbada pelo protestantismo. Cristãos, Calvinos e Puritanos acreditaram que a riqueza material seria demonstração de saúde espiritual, e a pobreza, conseqüentemente, doenças e males do espírito Oliveira (1997).

Observamos que paralelo às transformações nos dogmas religiosos, o sistema urbano-industrial trouxe às práticas trabalhistas da civilização ocidental um novo sentido. O conceito de trabalho medieval que relacionava o tempo a um caráter sagrado é alterado para um sentido profano a partir da Idade Moderna. Tempo é dinheiro - time is money - é a expressão máxima do sistema produtivo capitalista. A industrialização crescente, os aspectos da produção e da mais-valia, a mercadorização e coisificação do homem são características deste sistema econômico, gerando, progressivamente, uma sociedade que ressalta como representação maior da vida o trabalho, e inibe o lúdico como direito à felicidade, sustentando um discurso de atrelamento entre a felicidade almejada e o aumento de produção.

A diminuição da jornada de trabalho é uma luta histórica que esbarra no preconceito e na mitificação em torno da trilogia tempo/trabalho/lazer. No Brasil, apenas na segunda metade da década de 1920 é que passa a haver alguma regulamentação sobre férias. Os trabalhadores obtiveram, em alguns períodos, estas conquistas, atendendo, porém, sempre aos interesses da acumulação capitalista. A carta Del Lavoro, elaborada pelo governo fascista de Mussolini serve, no Brasil, para a elaboração da legislação trabalhista no governo Vargas. Sob este aspecto o lazer também é normatizado bem como as práticas desportivas. Tal fato impediria que o aumento do número de horas disponíveis inclusive para o lazer oportunizasse o crescimento do mal estar causado pela injustiça social, colocando em questão o direito à preguiça, que comprovadamente, contribui para o equilíbrio individual e coletivo e é negado à maioria.

O pensamento que está historicamente no poder - mesmo atualmente na sociedade pós-industrial, sociedade do conhecimento - entende que disponibilizar horas para o lazer desestabiliza os valores de felicidade e harmonia difundidos pela ideologia 
capitalista. Diga-se de passagem, existe uma parcela significativa de governantes que entende lazer e consumo como sinônimos. Assim afirma Oliveira (1997, p. 968)

a desautomatização humana só terá início de fato quando for permitido que o homem expresse sua ludicidade nos diferentes momentos da materialização de sua existência, sem esmagamento sistemático do ludens pela supervalorização imatura do faber.

O lazer é, portanto, aqui entendido como resultado do tipo de organização sócio-econômica urbano-industrial e, simultaneamente, atua sobre tal organização como implementador de novos valores, pensamentos, práticas que contestam esta mesma lógica organizacional. Para que isto aconteça é necessário à construção de consciências críticas bem como de políticas públicas que venham atender as necessidades concretas dos sujeitos na sociedade que queremos.

A educação para o lazer em seu sentido amplo, que ocorre na família, na rua, na igreja, no sindicato, nos clubes, parques, praças entre outros espaços, e em seu sentido restrito, na escola é importante referência quando pensamos na construção e consolidação de consciências críticas, criativas e questionadoras. Devendo ser compromisso de todos aqueles que se empenham na transformação social a assunção plena dos desafios colocados na perspectiva de contribuir para esta transformação onde a inclusão sócio-cultural de grupos excluídos a exemplo pessoas com deficiência entre outros grupos já mencionados neste artigo, seja objetivo maior a ser alcançado.

\begin{abstract}
The present paper focuse on the perpective of a critical discussion about Physical Education targeted on leisure, aiming at contrubuting to widen the required on the significance, the characristics, the consequences and the potentialities of leisure in the consuming society, though not intending to settle the matter. With this in mind, we chose an approach of the concepts of time and work in modern society as well the relationship between this trilogy and the right of minorities to participate. These concepts are fundamental to understand the characteristics aspects of leisure from a cultura point of view.
\end{abstract}

Key-Words: Leisure; Time; Work. 


\section{Referências Bibliográficas}

BRAMANTE, A. C. Recreação e lazer: o futuro em nossas mãos. In: MOREIRA, W. W. (Org.). Educação Física \& esportes: perspectivas para o século XXI. Campinas: Papirus, 1992.

CAPRA, F. O ponto de mutação. São Paulo: Cultrix, 1985.

CHAUÍ, M. Introdução. In: LAFARGUE, P. O direito a preguiça. São Paulo: Hucitec: ano. p. $9-56$

GUTIERREZ, G. L. A crise de paradigmas: sai de cena o trabalho e entra o lazer. In: BRUHNS, H. T.; GUTIERREZ, G. (Org.). Representações do lúdico. Campinas: Autores Associados, 2001. p. 91- 103.

GRAMSCI, A. Concepção dialética da história. 10. ed. Rio de Janeiro: Civilização Brasileira, 1995.

IANNI, O. O príncipe eletrônico. Revista Cultura Vozes, São Paulo, p. 05-29, 1999.

JAPIASSÚ, H; MARCONDES D. Dicionário básico de filosofia. 3. ed. rev. amp. Rio de Janeiro: Jorge Zahar, 1996.

LENHARO, A. Sacralização da política. Campinas: Papirus, 1986.

MARCELLINO, N. C. Lazer e educação. Campinas: Papirus, 1990.

. O lazer, sua especificidade e seu caráter interdisciplinar. Revista Brasileira de Ciências do Esporte, n. 1/3, p. 314-315.

. Lazer: formação e atuação profissional. Campinas: Papirus 1995

MARCUSE, H. Eros e civilização. Rio de Janeiro: Zahar, 1968.

MENEZES, A. B. Figuras do feminino na canção de Chico Buarque. São Paulo: Ateliê, 2000.

. Desenho mágico: poesia e política em Chico Buarque. São Paulo: Ateliê, 1995.

MONAKATA, K. A legislação trabalhista. São Paulo: Brasiliense, 1981.

OLIVEIRA, C. B. Reflexões acerca do lazer em suas diferentes dimensões: Da proposta teórica a prática na Universidade. In: CONGRESSO BRASILEIRO DE CIÊNCIAS DO ESPORTE, 10. Goiânia, 1997. Anais ... Goiânia, 1997. p. 966-970. 
SILVA, T. T. Os novos mapas culturais e o lugar do currículo numa paisagem pósmoderna. In: Identidades terminais. Petrópolis: Vozes, 1996.

Políticas sociais e os trabalhadores. Debate Sindical, ano 3, n. 11, out. 1989. 